aged between 20 and 30. Many of the fathers had criminal records and were unemployed at the time of the incident. In contrast to what might be thought, the families were usually small. The children battered were all very young, and over half of them were under a year old. That the victims of such assaults are subject to grave injury is now abundantly documented, and at least one child batterer in this country has been convicted of murder. ${ }^{4}$

The violence of the assaults and the infancy of the victims to some extent set these cases apart from other ill-treatment to which children may be subjected, though the boundaries of the syndrome cannot be regarded as clearly defined. But the need to be on the look-out for it is undoubted. For apart from the risk that a subsequent child may be assaulted there is the considerable possibility that the same child, battered once, will be battered again. The report gives some unfortunate examples of how doctors in general practice and hospitals failed to spot the nature of the case, and it also notes that "the unsatisfactory aftercare arrangements made by many hospitals despite the evidence of repeated, unexplained injury is disturbing."

The course a doctor should take when he finds himself in charge of a "battered baby" is subject to certain ethical restraints, but, as a memorandum from the British Paediatric Association $^{5}$ observed, doctors as well as being medical advisers have a duty to perform as citizens. In general the children's department of the local authority should be contacted rather than the police. What is now clear is that these cases are commoner than any ordinary person might think, and doctors have an essential role in diagnosing them correctly and taking preventive action.

\section{Human Placental Lactogen}

Several diagnostic tests for insufficiency of the placenta's function have been described. Recently a new one has appeared on the scene-human placental lactogen (H.P.L.).

First described in $1962,{ }^{1}$ human placental lactogen is a protein whose structure is similar to, but not identical with, that of human growth hormone. It has a similar molecular weight and amino-acid composition ${ }^{2}{ }^{4}$ and will react with antisera to growth hormone. ${ }^{14}$ It appears in the trophoblast very early in pregnancy ${ }^{5}$ and reaches measurable levels in maternal plasma by the sixth week. ${ }^{6-8}$ The levels then rise steadily, reaching a plateau during the third trimester. After delivery it disappears rapidly from the circulation. ${ }^{6-10}$ Human placental lactogen can be found in the mother's urine, ${ }^{11}$ in the amniotic fluid, ${ }^{11}$ and in cord blood. In the last the levels are much lower than in the maternal circulation. $^{6} 811$ It is also found in the blood of patients with trophoblastic tumours, but at much lower levels than those associated with normal pregnancy. ${ }^{6}$ Taken together, these findings suggest that H.P.L. is produced exclusively by the placenta, with no contribution from either the foetus or the mother's pituitary.

The physiological role of H.P.L. in man is uncertain. In experimental animals it has some growth-promoting activity, ${ }^{3-5}$ considerable lactogenic activity, ${ }^{1}$ and similar effects to those of growth hormone on carbohydrate and lipid metabolism. $^{312}$ In normal pregnancy production seems to be largely autonomous. The administration of either glucose or insulin has no effect on H.P.L. levels, ${ }^{6}$ in contrast to the changes found with growth hormone. ${ }^{13} 14$ In non-pregnant women it has been shown to have a diabetogenic effect, ${ }^{15}$ and it may be responsible for the exacerbation of diabetes which occurs in pregnancy.

The only method for determining the concentration of human placental lactogen in blood is by radioimmunoassay. Several techniques have been described, and the results reported by different laboratories cannot be compared directly, for there is at present no reference standard. Until this is available, each laboratory has to establish its own range of normal values. Apart from the problems of standardization the assay is relatively simple, since the hormone is a good antigen and readily iodinated. The simplicity and speed of assay may explain the recent increase of interest in the levels of this hormone as a measure of placental function.

A relationship between levels of placental lactogen in the blood and the weight of the placenta has been reported ${ }^{16}{ }^{17}$ and disputed. ${ }^{8}$ There is also disagreement about H.P.L. levels in diabetic pregnant women, for whom one group of workers has reported levels consistently higher than normal, ${ }^{17}$ while another has found no significant change. ${ }^{10}$ If there is a genuine correlation between H.P.L. levels in blood and placental mass, then it is possible that measurement of the levels might be an indicator of placental insufficiency. Two recent studies have yielded conflicting evidence on the value of this estimation in clinical practice. In a paper from Boston B. N. Saxena and colleagues, ${ }^{17}$ have reported low levels in three patients with diabetes asociated with placental insufficiency, in two patients with abruptio placentae, and in five in whom there was retarded foetal growth with no apparent cause. Four women with prolonged pregnancy showed a gradual fall in H.P.L. levels after 40 weeks of gestation. Two patients in whom there was clinical evidence of foetal distress during labour had shown decreasing levels during the last month of pregnancy. In addition, levels lower than normal were found in five women several days before spontaneous abortion. These results would suggest that the test is of considerable prognostic value in abnormal pregnancies. A rather different picture is painted by N. A. Samaan and his colleagues from Iowa. ${ }^{18}$ Fourteen diabetic patients all showed normal values. Of three patients with rhesus immunization two had normal values and one below normal. In three patients with toxaemia, whose premature

1 Josimovich, J. B., and MacLaren, J. A., Endocrinology, 1962, 70, 209. Catt, K. J., Moffatt, B., Niall, H. D., and Preston, B. N., Biochemical

3 Friesen, H., Endocrinology, 1965, 76, 369.

Kaplan, S. L., and Grumbach, M. M., Fournal of Clinical Endocrinology and Metabolism, 1964, 24, 80.

5 Josimovich, J. B., and Atwood, B. L., American fournal of Obstetrics and Gynecology, 1964, 88, 867.

6 Samaan, N., Yen, S. C. C., Friesen, H., and Pearson, O. H., fournal of Clinical Endocrinology and Metabolism, 1966, 26, 1303.

Saxena, B. N., Refetoff, S., Emerson, K., and Selenkow, H. A., American fournal of Obstetrics and Gynecology, 1968, 101, 874. A.

s Spellacy, W. N., Carlson, K. L., and Birk, S. A., American fournal of Obstetrics and Gynecology, 1966, 96, 1164.

Kaplan, S. L., and Grumbach, M. M., Fournal of Clinical Endocrinology and Metabolism, 1965, 25, 1370.

10 Beck, P., Parker, M. L., and Daughaday, W. H., fournal of Clinical Endocrinology and Metabolism, 1965, 25, 1457.

11 Kaplan, S. L., and Grumbach, M. M., Science, 1965, 147, 751.

12 Riggi, S. J., Boshart, C. R., Bell, P. H., and Ringler, I., Endocrinology 1966, 79, 709.

13 Roth, J., Glick, S. M., Yalow, R. S., and Berson, S. A., Metabolism, $1963,12,577$.

14 Hunter, W. M., Friend, J. A. R., and Strong, J. A., fournal of Endocrinology, 1966, 34, 139.

15 Samaan, N., Yen, S. C. C., Gonzalez, D., and Pearson, O. H., Fournal of Clinical Endocrinology and Metabolism, 1968, 28, 485.

${ }_{16}$ Sciarra, J. J., Sherwood, L. M., Varma, A. A., and Lundberg, W. B. American fournal of Obstetrics and Gynecology, 1968, 101, 413 .

Saxena, B. N., Emerson, K., and Selenkow, H. A., New England Fournal of Medicine, 1969, 281, 225 .

is Samaan, N. A., Bradbury, J. T., and Goplerud, C. P., American fournal of Obstetrics and Gynecology, 1969, 104, 781 . 
babies died, one had normal levels of H.P.L., one had higher than normal levels, and one had low levels. These authors were therefore unimpressed with the general value of such determinations.

The chief contender among diagnostic tests for placental insufficiency is the determination of urinary oestriol levels. This is now well established, and in contrast to H.P.L. it measures the function of the foetus and placenta together as a unit. However, if measurement of H.P.L. proves to be of similar value, then it offers the advantages that it can be performed on single blood samples and that larger numbers of tests can be carried out. But the evidence on its value is conflicting and further work on it is needed.

\section{Massive Haemoptysis}

It is perhaps not widely recognized that when haemoptysis is massive death is common. ${ }^{1-4}$ The idea that reassurance by the physician is the best treatment, since even copious haemorrhages will cease in time, ${ }^{5}$ may encourage the view that conservative management is all that is required. But a study reported by J. A. Crocco and his colleagues ${ }^{1}$ is a timely reminder that massive haemoptysis is serious and potentially fatal. With massive haemoptysis defined as the loss of 600 $\mathrm{ml}$. or more of blood within $\mathbf{4 8}$ hours, overall mortality among 67 patients was $37 \%$; if blood-loss was at the rate of more than $600 \mathrm{ml}$. in 16 hours, it rose to $75 \%$. These figures emphasize the dangers in too much reliance on conservative management.

It is difficult to be precise about the relative frequency of the causes of massive haemoptysis, because reported series are often biased in one direction or another, but tuberculosis (both active and inactive) is certainly prominent, while lung abscess, bronchiectasis, and bronchial carcinoma are other common causes. Necrotizing arteritis has also been associated with massive haemoptysis, ${ }^{6} 7$ and bleeding from lung abscess seems to be particularly lethal. ${ }^{18}$ Rarer causes are broncholiths, pulmonary infarct, trauma, and mycetomata in association with pulmonary aspergillosis. Massive bleeding may also occur in patients with a tracheostomy tube in situ. Crocco and his colleagues showed that there was no significant variation in mortality according to age and also that $87 \%$ of their patients had had previous episodes of haemoptysis. Further analysis showed that the mortality increased with the rate of bleeding, so it is clearly important to avoid delay in making decisions about treatment.

Massive haemoptysis must be regarded as a medical emergency and calls for immediate investigation of the patient. Early chest radiography is essential to try to identify

' Crocco, J. A., Rooney, J. J., Fankushen, D. S., DiBenedetto, R. J., and Lyons, H. A., Archives of Internal Medicine, 1968, 121, 495. Ehrenhaft, J. L., and Taber, R. E., Fournal of Thoracic and Cardiovascular Surgery, 1955, 30, 275.

Ford, J. M., Clauss, R. H., Al Askari, S., and Wylie, R. H., fournal of Thoracic and Cardiovascular Surgery, 1958, 35, 341.

4 Linberg, E. J., American Surgeon, 1964, 30, 158

Rubin, E. H., and Rubin, M., Thoracic Diseases, 1961, p. 925.

- Fisher, A. M., and Shelley, W. M., Archives of Internal Medicine, 1966, 117, 412.

Storey, C. F., fournal of Thoracic and Cardiovascular Surgery, 1955, 30, 284.

- Ray, E. S., Virginia Medical Monthly, 1947, 74, 121.

- Pursel, S. E., and Lindskog, G. E., American Review of Respiratory Diseases, $1961,84,329$.

10 Randolph, H., Diseases of the Chest, 1955, 28, 416. the site and cause of bleeding, and continuous monitoring is invaluable. Adequate supplies of blood for transfusion must be made immediately available. Several forms of treatment to control bleeding have been advocated-oestrogens, vasopressin, protamine sulphate, vitamin $\mathrm{K}$, and calcium gluconate among others-but proof of their efficacy is lacking. The importance of bronchoscopy in both diagnosis and treatment is often forgotten, and there is a common misconception that bronchoscopy is valueless while the patient is bleeding. Crocco and his colleagues identified the site of bleeding at bronchoscopy in 65 out of 67 patients, and S. E. Pursel and G. E. Lindskog found the site of haemorrhage in 18 out of 21 patients who were examined while they were still bleeding. ${ }^{9}$ Bronchoscopy is also valuable in treatment, because death is frequently due to asphyxia. ${ }^{3}$ Removal of clot from bronchi is clearly important. Tracheostomy and ventilation may sometimes be required.

There is clearly a role for surgical treatment, and this is especially so if the rate of bleeding exceeds $600 \mathrm{ml}$. in 16 hours ; a previous history of significant haemoptysis may be an added indication. Haemorrhage from non-malignant lung abscess seems to be particularly lethal, and early resection of such lesions seems to improve the prognosis. ${ }^{14}$ Resection may also be safely carried out in the presence of active tuberculosis provided the patient receives effective chemotherapy cover. Massive haemoptysis occurs in some patients who are unsuitable for resection because of inadequate pulmonary reserve or other causes ; bedside determination of ventilatory function may be helpful, though it may be difficult to evaluate the results in patients with blood in the bronchial tree.

Massive haemoptysis fortunately is rare even in the experience of specialized thoracic units. It alarms patients greatly, and thus reassurance is an important part of management. But alone it is not enough, and immediate evaluation of the problem is essential, bronchoscopy occupying a central place in management. ${ }^{129}$ Timely surgical treatment, when practicable, may save many lives.

\section{Hypertension in Patients on Regular Dialysis}

Richard Bright ${ }^{1}$ first observed hypertrophied left ventricles in patients dying with terminal renal disease 133 years ago, but we have little information why hypertension appears in this state. The technique of maintenance dialysis, which prolongs life beyond terminal renal failure, has now provided information which bears on our understanding of hypertension in general.

The first and perhaps still the most startling observation was that even the most severe forms of accelerated hypertension became reversible without drugs in patients on regular dialysis. $^{2}$ This result is achieved when the intake of salt and water is rigidly restricted in adequately dialysed patients. In this situation there is a good correlation between exchangeable sodium and blood pressure. ${ }^{3}$ Within a year or two dialysis units were regarding young patients with rapid terminal deterioration in association with accelerated hypertension as the ones who would most quickly and successfully be returned to health, including a normal blood pressure, simply by adequate regular dialysis. 